\title{
Research Paper: Investigation of Reactive Blue 21 Dye Removal Using Multi-Wall Carbon Nanotubes: Isotherm and Kinetics
}

\author{
Marzieh Bagheri ${ }^{1^{*}} \bigcirc$, Mohammad Nasiri² ${ }^{2}$, Marzieh Pavir $^{1}$
}

1. Department of Chemical Engineering, Jami Institute of Technology, Isfahan, Iran.

2. Department of Chemistry and Chemical Engineering, Malekashtar University of Technology, Tehran, Iran.

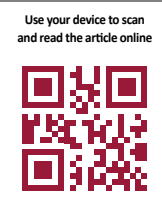

Citation: Bagheri M, Nasiri M, Pavir M. Investigation of Reactive Blue 21 Dye Removal Using Multi-Wall Carbon Nanotubes: Isotherm and Kinetics. 2017; 3(4):205-212. https://doi.org/10.32598/jamsat.3.4.205

https://doi.org/10.32598/jamsat.3.4.205

Article info:

Received: 19 Mar 2017

Accepted: 01 Aug 2017

Keywords:

Wastewater, Adsorption, MWCNTs, Isotherm

\begin{abstract}
A B S T RACT
Objectives: Increasing use of colored materials in various industries and their discharge into the environment through industrial wastewater, can create many problems for humans and other beings. In the present study, the effect of removing Reactive Blue 21 (RB 21) dye using Multi-Wall Carbon Nanotubes (MWCNTs) as adsorbent is studied.

Materials \& Methods: The research was carried out on a laboratory scale and in a discontinuous system. Factors affecting dye removal such as $\mathrm{pH}$, adsorption dose, concentration of dye and contact time were investigated. Also two Langmuir and Freundlich isotherms were studied in different concentrations of dye. UV-visible spectrophotometer was used to determine the dye removal. It should be noted that all experiments were carried out at $25^{\circ} \mathrm{C}$.

Results: Regarding the results in an environment with $\mathrm{pH}=3$, in 30 minutes time, with $0.05 \mathrm{~g} / \mathrm{L}$ of adsorbent (MWCNTs) to remove $50 \mathrm{~mL}$ of RB 21 dye with a concentration of $40 \mathrm{ppm}$, the best adsorption and maximum dye removal was obtained as $81 \%$.

Conclusion: According to the results of the experiments, it was found that MWCNTs are very suitable for comparison with other synthetic adsorbents used to remove RB 21 dye.
\end{abstract}

\section{Introduction}

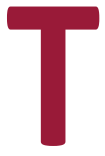

he entry of dyes waste from various industries such as textiles, paper, leather and plastics is one of the environmental problems. Toxicity of this group of substances brings irreparable damage to the environment, humans and other living organisms [1, 2]. In addition, the effluent produces irreparable effects by preventing the penetration of light into the water and disturbing the photosynthesis process in aquatic ecosystems [3]. Due to their toxic properties, mutagenesis and carcinogenicity, some of the colors or their combinations resulting from their decomposition require further research to be removed from the environment.

Reactive dyes are one of the most widely used dyes in the textile industry. Reactive dyes have high molecular weight and aromatic rings. As a result, they have more stability, and their removal from wastewater is more

* Corresponding Author:

Marzieh Bagheri, PhD

Address: Department of Chemical Engineering, Jami Institute of Technology, Isfahan, Iran.

Tel: +98 (913) 4111913

E-mail: miss.bagheri40@yahoo.com 
difficult $[4,5]$. So far, various chemical, biological, and physical methods have been used to separate dyes from different types of wastewater [6].

The most commonly chemical methods used to remove dyes include coagulation, preconcentration, advanced oxidation, and electrochemical. One of the problems of chemical methods, such as coagulation is the high solubility of colors in aqueous solutions [7]. Also, the removal efficiency is usually low in biological methods that use fungi and bacterial types. Among the physical methods, absorption is the most important one which is used for removal dyes [8]. In this method, various adsorbents such as activated carbon $[9,10]$, bentonite [11], nanoclays, chitosan [12], montmorillonite [13] and carbon nanotubes [14-21] have been used to remove dyes. In the present work, for the first time, Multi-wall Carbon Nanotubes (MCNTs) was used for removal of reactive blue 21 and studied the effective factors on the adsorption of this type of dye on the surface of the nanotubes.

\section{Materials and Methods}

The reactive blue 21 dye was investigated in this study with a molecular weight of $1079.549 \mathrm{~g} / \mathrm{mol}$ and the chemical formula $\mathrm{C}_{40} \mathrm{H}_{25} \mathrm{CuN}_{9} \mathrm{O}_{14} \mathrm{~S}_{5}$ (provided by Alvan Company of Hamadan, Iran). The chemical structure of this material is shown in Figure 1. MWCNTs was purchased as adsorbent with purity greater than 95\%, 20 $30 \mathrm{~nm}$ in diameter, specific surface of about $1315 \mathrm{~m}^{2} / \mathrm{g}$, inter-shell distance of about $0.34 \mathrm{~nm}$ and in the planer sheet about $0.142 \mathrm{~nm}$ (from American Cheap Tubes Inc.).

In order to investigate the effect of $\mathrm{pH}$ on the dye removal rate, the $\mathrm{pH}$ meter of Zag Chemieh Company from

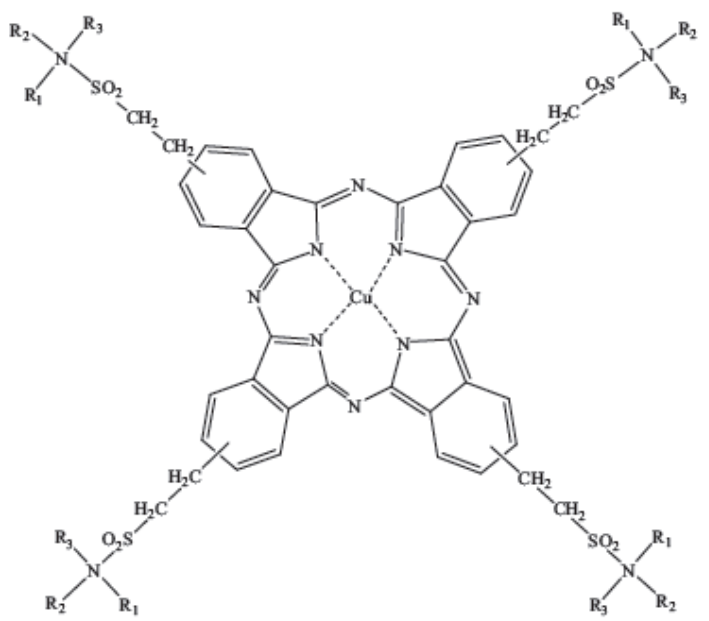

Figure 1. Chemical structure of reactive dye blue 21

JAMSAT
Iran was used. For $\mathrm{pH}$ adjustments, the sulfuric acid 0.1 $\mathrm{M}$ and sodium hydroxide $0.1 \mathrm{M}$ (purchased from Merck Company from Germany) were used. The digital scale extend model of Taiwan was used to measure the material with a precision scale of $0.001 \mathrm{~g}$. In order to homogenize the solutions, the Heater Stirrer (made in USA) was used. To isolate from the centrifuge, the EBI20 model of the Hettich Company in China was used. A single-radiation UV-visible spectrophotometer (UV-2100PC, JENUS, China) was used to determine the amount of dye removal.

\section{Calibration curve}

In order to prepare the standard solution, the first mother solution (1000 ppm) was made, then other solutions were prepared by diluting this solution. For the curve calibration, solutions containing concentrations of the stock solution were made (Figure 2). For each solution, the adsorption displayed on the UV-visible spectrophotometer was read at maximum wavelength (The maximum wavelength for the RB 21 dye was obtained at $343 \mathrm{~nm}$ ). Also, to determine the percentage of dye removal efficiency of aqueous solutions using MWCNTs, Equation (1) was used:

(1) $\% R=\left[\frac{\left(C_{p}-C_{0}\right)}{C_{0}}\right] \times 100$

Where $\mathrm{R}$ is dye removal efficiency, $\mathrm{C}_{\mathrm{p}}$ is the concentration of residual dye after addition of adsorbent and is the primary dye concentration in aqueous solution.

The RB 21 adsorption capacity was calculated by Equation (2):

(2) $q_{e}=\frac{\left(C_{0}-C_{e}\right)}{M} \times V$

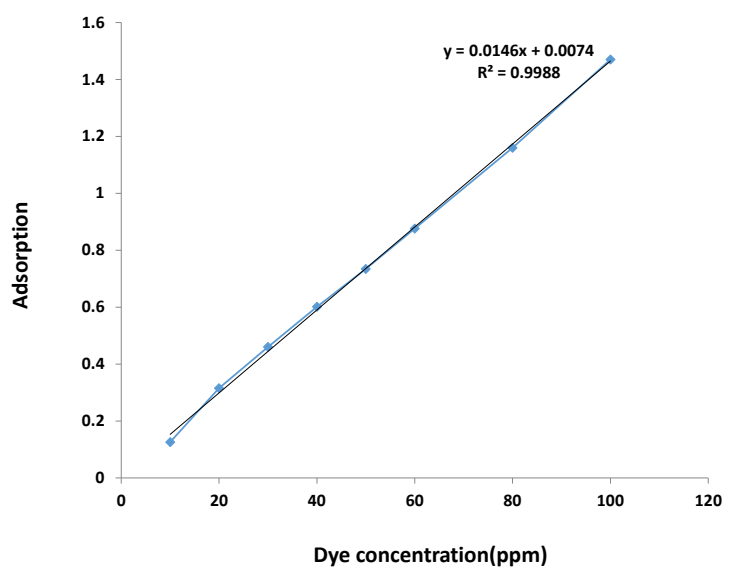

JAMSAT
Figure 2. Calibration curve for RB 21 dye in a concentration range of 10 to $100 \mathrm{ppm}$ 
Where $C_{e}$ is equilibrium concentration, $M$ is MWCNTs in $\mathrm{mg} / \mathrm{mg}$ and $\mathrm{V}$ is the volume of solution required.

Investigating isotherms of the dye removal process by adsorbent

The adsorption isotherms are used to describe how pollutants react with adsorbent materials. Isotherms usually indicate the relation between dyes adsorbed mass at constant temperature with adsorbent mass in equilibrium. The isothermal equations used to analyze the experimental data and describe the equilibrium in adsorption are Langmuir and Freundlich isotherms. These models are usually used to provide a view of the mechanism, surface properties and adsorption tendency. Equation (3) was used to calculate Langmuir isotherm:

(3) $C_{e} / q_{e}=\left[1 / b q_{\max }+{ }^{C} / q_{\max }\right]$

Where $q_{e}$ is the equilibrium adsorption capacity, $C_{e}$ is the equilibrium concentration, $\mathrm{q}_{\max }$ is the maximum adsorption capacity and $b$ is the correlation coefficient [22].

Also equations (4) and (5) was used to calculate the Freundlich isotherm.

(4) $q_{e}=K_{f c_{e}^{1 / n}}$

(5) $\log q_{e}=\log K_{f}+1 / n \log C_{e}$

Where $\mathrm{K}_{\mathrm{f}}$ and $\mathrm{n}$ are the Freundlich constants that relate to the adsorption capacity and the adsorption intensity [23].

Investigating surface adsorption kinetics

In order to provide information on the factors affecting the reaction speed, it is necessary to determine mechanisms for

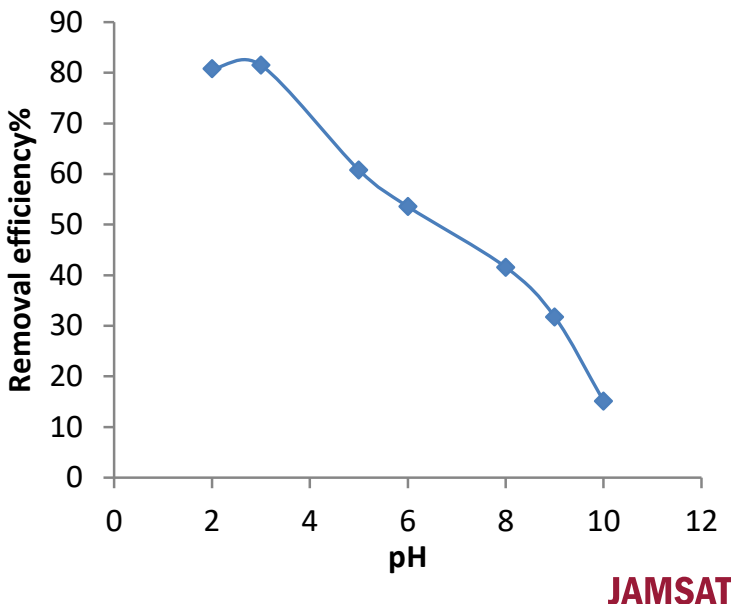

Figure 3. The effect of $\mathrm{pH}$ on the percentage of removal of RB 21 dye $(40 \mathrm{ppm})$ by MWCNTs $(0.05 \mathrm{~g})$ controlling the adsorption process, such as surface adsorption, chemical reaction and kinetic evaluation penetration mechanisms. First and second order kinetic models are widely used in resources for the adsorption process. The first-order kinetic model shows that penetration occurs from within a layer and based on solid capacity while the second-order kinetic model shows that the chemical adsorption is a moderator speed step which controls the adsorption processes and based on adsorption on a solid phase. The kinetic model of the first-order equation is as follows:

(6) $\ln \left(q_{e}-q_{t}\right)=\ln q_{e}-k_{1 t}$

Where $\mathrm{q}_{\mathrm{e}}$ is amount of absorbed material on MWCNTs in equilibrium ( $\mathrm{mg} / \mathrm{g}$ ), $\mathrm{q}_{\mathrm{t}}$ is the amount of adsorbed material at $t$ time and $\mathrm{K}_{1}$ is equilibrium constant kinetic of the first order ( $\mathrm{L} / \mathrm{min})$. The kinetic model of the second order equation is as follows:

$$
\text { (7) } \frac{t}{q_{t}}=\frac{1}{k_{2} q_{e}{ }^{2}}+\left(\frac{1}{q_{e}}\right) t
$$

Where $\mathrm{K}_{2}$ is equilibrium constant kinetic of the second order (L/min) [24].

\section{Results}

\section{Effect of $\mathrm{pH}$ on dye removal}

One of the parameters that can effect on the dye removal rate of the adsorbent is the $\mathrm{pH}$ of the test solution. Therefore, to evaluate the effect of $\mathrm{pH}, 50 \mathrm{~mL}$ of RB 21 dye solution (40 ppm) was used. By adding the appropriate amounts of $\mathrm{HNO}_{3}$ and $\mathrm{NaOH} 1.0 \mathrm{M}$ solution, the $\mathrm{pH}$ of solutions was adjusted within the range of 2 to 10 . Then, the amount of $0.05 \mathrm{~g}$ of MWCNTs as adsorbent was added to each of the desired solutions and each of the solutions was placed on a

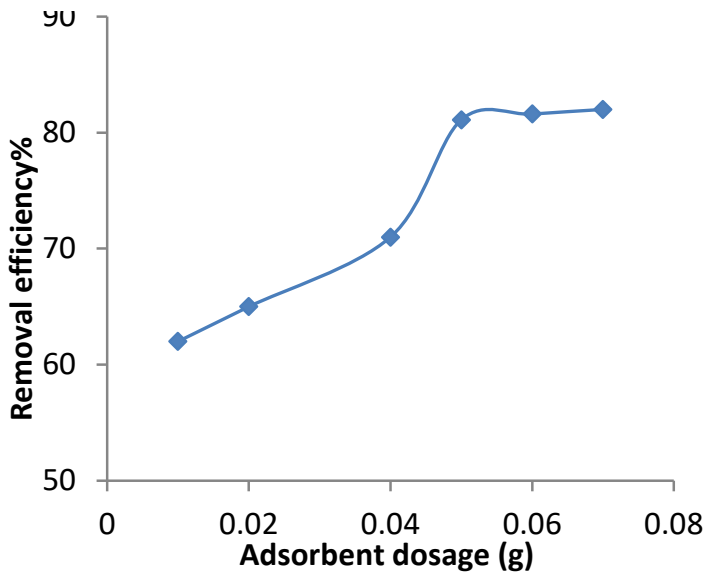

JAMSAT

Figure 4. Effect of MWCNTs dosage on the percentage of removal of RB 21dye (40 ppm) 


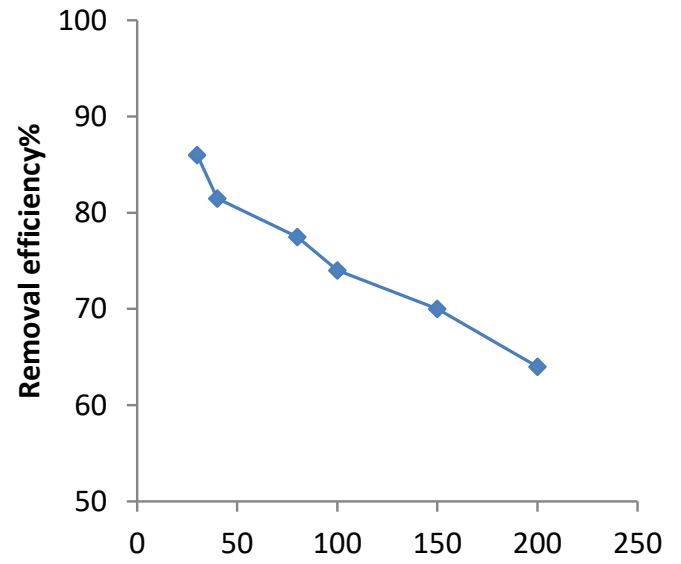

JAMSAT

Figure 5. Effect of the concentration of dye RB 21 on dye removal by MWCNTs $(0.05 \mathrm{~g})$

magnetic stirrer for 60 minutes at the laboratory temperature. The samples were then separated by centrifuge and filtered with filter paper. Finally, the adsorption of all solutions was measured by UV-visible spectrophotometer and compared with the initial absorbance (before adding adsorbent to color solution). Then the removal percentage was plotted as a function of $\mathrm{pH}$ in the range of 2-10 (Figure 3).

\section{Effect of adsorbent dosage on dye removal}

The effect of adsorbent dosage on different levels of MWCNTs $(0.1,0.2,0.04,0.06$, and $0.07 \mathrm{~g})$ was investigated on RB 21 dye. In each experiment, $50 \mathrm{~mL}$ of dye solution with an initial concentration of $40 \mathrm{ppm}$ was used. The experiments were carried out at room temperature at constant stirring speed for 60 minutes. The results are shown in Figure 4.

Effect of initial dye concentration on dye removal

To investigate the effect of dye solution concentration on dye removal efficiency by MWCNTs as adsorbent, 5

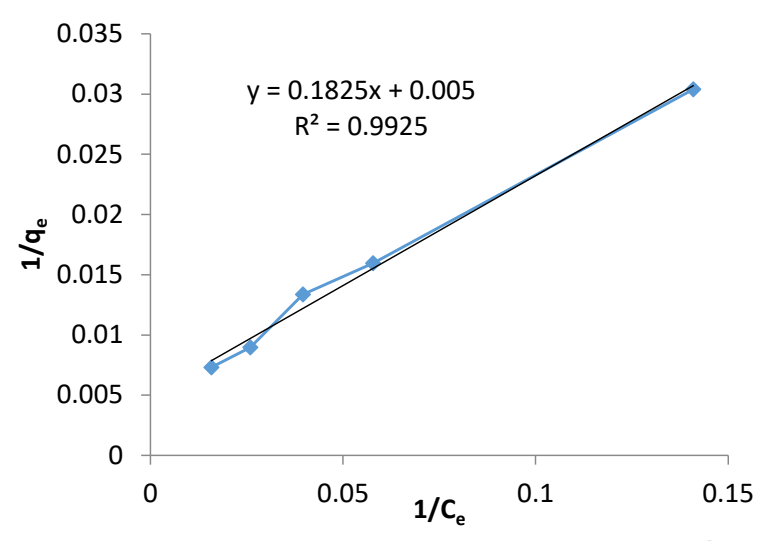

JAMSAT

Figure 7. Langmuir isotherm chart for RB 21 dye removal by MWCNTS

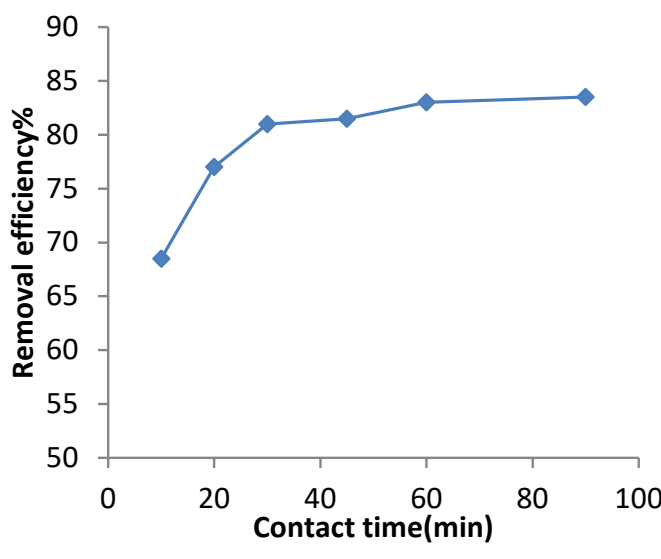

JAMSAT

Figure 6. Investigating the effect of contact time on RB 21 dye removal (40 ppm) by MWCNTs ( $0.05 \mathrm{~g})$

samples of $50 \mathrm{~mL}$ solution of dye solution at concentrations of $40,80,100,150$ and 200 ppm were prepared. All experiments were carried out at ambient temperature $\left(25^{\circ} \mathrm{C}\right)$ with a constant stirrer for 60 minutes.

\section{Effect of contact time on dye removal}

Another factor influencing the amount of dye removal by adsorbent is adsorbent contact time with dye solution. The contact time effect on the dye adsorption process was carried out at $0.05 \mathrm{~g}$ of adsorbent at ambient temperature $\left(25^{\circ} \mathrm{C}\right)$ on $50 \mathrm{~mL}$ of 40 ppm solution of RB 21 dye with a constant stirrer for 5 to 90 minutes.

Investigating isotherms of the removal dye process by adsorbent

The two models were used to examine the isothermal adsorption of RB 21 dye on MWCNTs (Figures 7 and 8).

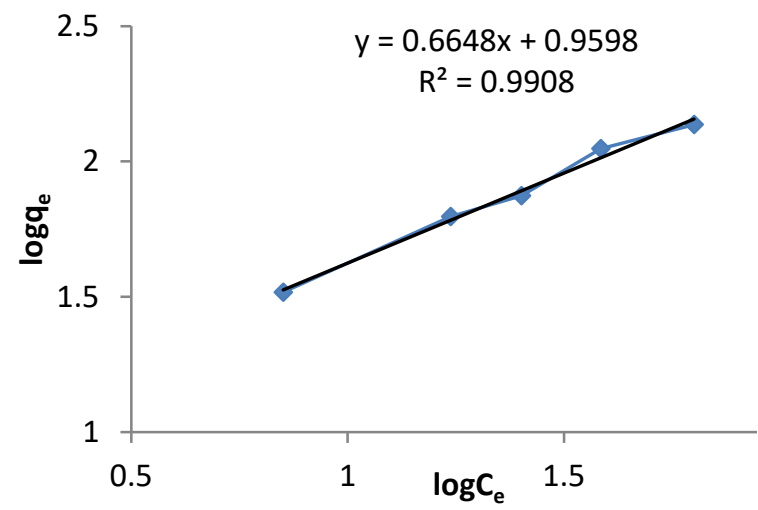

JAMSAT

Figure 8. Freundlich isotherm chart for RB 21 dye removal by MWCNTS 


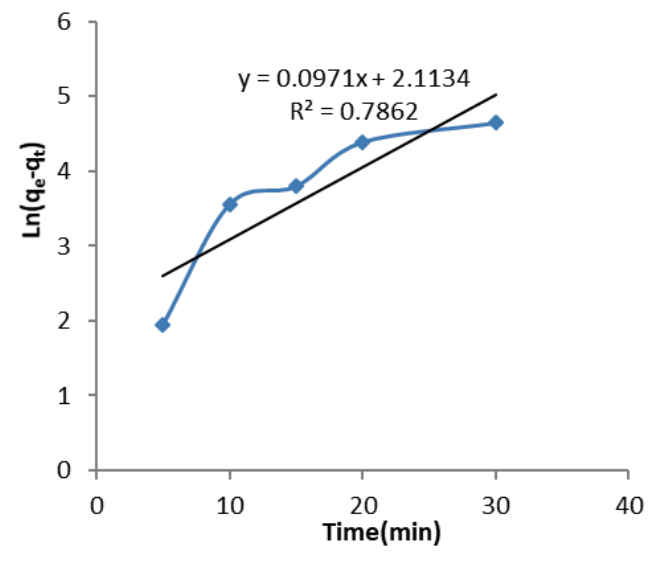

Figure 9. First-order order equation graph

JAMSAT

Investigating surface adsorption kinetics

By drawing the diagram In $\left(q_{e}-q_{t}\right)$, in terms of time, the constancy and $\mathrm{R}$ of the equation were calculated. Figure 9 represents the graph of the first-order equation. By drawing $t / q_{t}$ in terms of the time constants and $R$ equation were obtained through the second-order model (Figure 10).

\section{Discussion}

According to the results, the best removal rate of dye at $\mathrm{pH}=3$ was obtained and the highest adsorption efficiency was in acidic $\mathrm{pH}$. In addition, with the increase in the $\mathrm{pH}$ value, the efficiency of the adsorption process decreases significantly. It seems that the $\mathrm{OH}$ groups play an important role on the MWCNTs surfaces. So that in a $\mathrm{pH}$ of higher than 3, the bond between $\mathrm{OH}$ groups on the MWCNTs surfaces increases. This leads to an increase in negative charge at the MWCNTs surfaces and, as a result, reduces the efficiency of dye removing at a $\mathrm{pH}$ higher than 3 [25].

Table 1. Constants parameters and correlation coefficients $\left(R^{2}\right)$

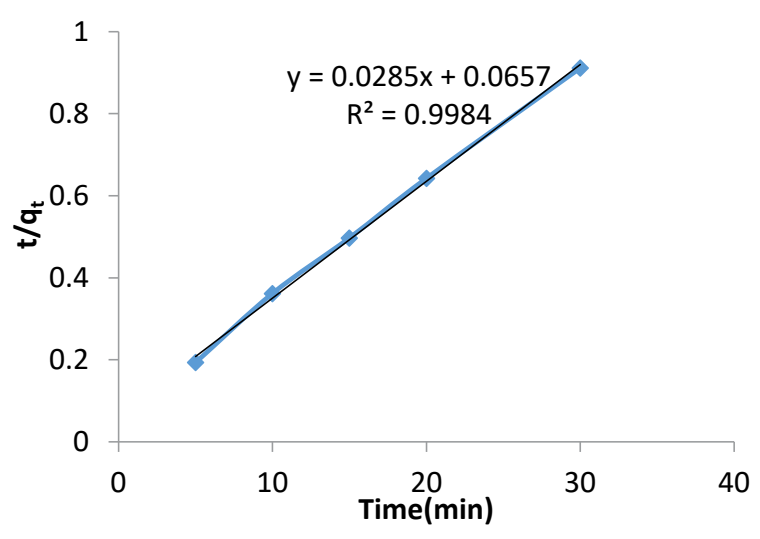

Figure 10. Second-order equation graph

JAMSAT

Based on the results, when the amount of MWCNTs ranged between 0.01 and $0.05 \mathrm{~g}$, the dye remove percentage increased from $60 \%$ to $81.5 \%$ and after that, no significant change was found. So the optimal amount in this experiment was 0.05 in each sample. By increasing the adsorbent dosage, the removal efficiency increased (Figure 4 ), because the number of active sites that can eliminate the molecules of dyes increase. According to Figure 5, the dye removal efficiency decreased with increasing dye concentration. At a concentration of $40 \mathrm{mg} / \mathrm{L}$, the highest dye removal percentage was observed (81.5\%). Because the adsorbent active sites are fixed, the percentage of adsorption decreases by increasing the dye concentration.

The results are shown in Figure 6. Whatever the contact time between the adsorbent and dye is longer, the dye substance finds more time to create more effective collisions, resulting in increased adsorption. In $30 \mathrm{~min}-$ utes, the highest removal efficiency was obtained (81\%). Based on the obtained results for this dye, the change in time from 30 to 90 minutes did not have a significant effect on dye adsorption [26]. By drawing the Langmuir

\begin{tabular}{ccccccc}
\hline & Freundlich & \multicolumn{3}{c}{ Langmuir } \\
\hline $\mathbf{R}^{2}$ & $\mathbf{k}_{\mathbf{f}}$ & $\mathbf{n}$ & $\mathbf{R}^{2}$ & $\mathbf{b}$ & $\mathbf{a}$ \\
\hline 0.9908 & 11.9 & 1.5 & 0.9925 & 200 & 0.027 \\
\hline
\end{tabular}

JAMSAT

Table 2. Constants of kinetic absorption equations

\begin{tabular}{ccrr} 
Equation & $\mathbf{R}^{2}$ & $\mathbf{K}$ & $\mathbf{q}_{\mathbf{e}}$ \\
\hline First-order equation & 0.044 & 0.81 & 0.78 \\
Second-order equation & 0.99 & 0.012 \\
\hline
\end{tabular}


and Freundlich curves and calculations performed using relationships the coefficients of these isotherms can be calculated for comparison. These coefficients are presented in Table 1. According to the calculated coefficients $\left(R^{2}\right)$ in Table 1, the removal of dye matter by multiple carbon nanotubes follows Langmuir's isotherm. In Table 2, the constants of linear kinetic forms have been reported for the first and second order equations.According to the values of $R^{2}$ obtained from the experimental results summarized in Table 2, the kinetic adsorption process has a good fit with the second order equation.

\section{Conclusion}

Due to the adsorption efficiency of the reactive Blue 21 dye by multi-wall carbon nanotubes in a discontinuous system depends on the process variables such as $\mathrm{pH}$, adsorbent amount, contact time, and initial dye concentration. The best dye removal conditions were calculated by changing each of the listed variables (one at the time method). The results were showed that the highest removal of RB 21 dye for $50 \mathrm{~mL}$ of solution dye with concentration of $40 \mathrm{ppm}$ at $\mathrm{pH}=3$ with adsorbent dose of $0.05 \mathrm{~g}$ and contact time of $\mathbf{3 0}$ minutes at laboratory temperature was $81.53 \%$. According to the results of the experiments, it was found that MWCNTs are very suitable as compared to other natural adsorbents used to remove the RB 21 dye. In this study, two Langmuir and Freundlich isotherms were investigated in different concentrations. The results showed that dye adsorption follows Langmuir model. Also, the results of the kinetic adsorption process showed that it followed the second-order model.

\section{Ethical Considerations}

\section{Funding}

This article has been extracted from MSc. thesis of Marzieh Pavir in the field of Chemical Engineering at Jami Institute of Technology, Isfahan, Iran. The authors appreciate Jami Institute of Technology for financial and logistic support.

\section{Conflict of interest}

The authors have declared no conflicts of interest.

\section{References}

[1] Aksu Z. Application of biosorption for the removal of organic pollutants: A review. Process Biochemistry. 2005; 40(3-4):997-1026. [DOI:10.1016/j.procbio.2004.04.008]

[2] Lucas MS, Peres JA. Degradation of reactive black 5 by Fenton/ UV-C and ferrioxalate/ H2O2/ solar light processes. Dyes and Pigments. 2007; 74(3):622-9. [DOI:10.1016/j.dyepig.2006.04.005]

[3] Santhy K, Selvapathy P. Removal of reactive dyes from wastewater by adsorption on coir pith activated carbon. Bioresource Technology. 2006; 97(11):1329-36. [DOI:10.1016/j.biortech.2005.05.016] [PMID]

[4] Balarak D, Pirdadeh F, Mahdavi Y. Biosorption of acid red 88 dyes using dried Lemna minor biomass. Journal of Science, Technology and Environment Informatics. 2015; 1(2):81-90. [DOI: 10.18801/ jstei.010215.10]

[5] Shokohi R, Samarghandi MR, Pourfarzi F, Siboni MS, Vahedi H. [Removal of Reactive Black 5 (RB 5) dye from aquatic solution by using of adsorption onto synthesized sodiumalginate magnetic beads (Persian)]. International Journal of Hydrogen Energy. 2011; 4(1):1-10.

[6] Crini G. Kinetic and equilibrium studies on the removal of cationic dyes from aqueous solution adsorption onto a Cyclodextrin Polymer. Dyes and Pigments. 2008; 77(2):415-26. [DOI:10.1016/j. dyepig.2007.07.001]

[7] Ghanizadeh Gh, Asgari Gh. [Removal of methylene blue dye from synthetic wastewater with bone char (Persian)]. Iranian Journal of Health and Environment. 2009; 2(2):104-13.

[8] Sarioglu M, Atay UA. Removal of methylene blue by using biosolid Global NEST Journal. 2006; 8(2):113-20. [DOI:10.30955/ gnj.000351]

[9] Hameed BH, Tan IAW, Ahmad AL. Equilibrium and kinetic studies on basic dye adsorption by oil palm fibre activated carbon. Chemical Engineering Journal. 2007; 127(1-3):111-9. [DOI:10.1016/j cej.2006.09.010]

[10] Oladoja NA, Aboluwoye CO, Akinkugbe AO. Evaluation of loofah as a sorbent in the decolorization of basic dye contaminated aqueous system. Industrial \& Engineering Chemistry Research. 2009; 48(4):2786-94. [DOI:10.1021/ie801207a]

[11] Dos Santos OA, Castellib CZ, Oliveirab MF, de Almeida Netob AF, da Silvab MG. Adsorption of synthetic orange dye wastewater in organoclay. Chemical Engineering Transactions. 2013; 32:307-12. [DOI:10.3303/CET1332052]

[12] Perju MM, Dragan ES. Removal of azo dyes from aqueous solutions using chitosan based composite hydrogels. Ion Exchange Letters. 2010; 3:7-11.

[13] Nogueira FG, Lopes JH, Silva AC, Gonçalves M, Anastácio AS, Sapag K, et al. Reactive adsorption of methylene blue on montmorillonite via an ESI-MS study.Applied Clay Science. 2009; 43(2):190-5. [DOI:10.1016/j.clay.2008.08.004]

[14] Gupta VK, Kumar R, Nayak A, Saleh TA, Barakat MA. Adsorptive removal of dyes from aqueous solution onto carbon nanotubes: A review. Advances in Colloid and Interface Science. 2013; 193 194:24-34. [DOI:10.1016/j.cis.2013.03.003]

[15] Mishra AK, Arockiadoss T, Ramaprabhu S. Study of removal of azo dye by functionalized multi walled carbon nanotubes. Chemi- 
cal Engineering Journal. 2010; 162(3):1026-34. [DOI:10.1016/j. cej.2010.07.014

[16] Yu H, Fugetsu B. A novel adsorbent obtained by inserting carbon nanotubes into cavities of diatomite and applications for organic dye elimination from contaminated water. Journal of Hazardous Materials. 2010; 177(1-3):138-45. [DOI:10.1016/j.jhazmat.2009.12.007]

[17] Machado FM, Bergmann CP, Fernandes THM, Lima EC, Royer B, Calvete $T$, et al. Adsorption of reactive red M-2BE dye from water solutions by multi-walled carbon nanotubes and activated carbon. Journal of Hazardous Materials. 2011;192(3):1122-31. [DOI:10.1016/j.jhazmat.2011.06.020]

[18] Yao Y, He B, Xu F, Chen X. Equilibrium and kinetic studies of methyl orange adsorption on multiwalled carbon nanotubes. Chemical Engineering Journal. 2011; 170(1):82-9. [DOI:10.1016/j. cej.2011.03.031]

[19] Rajabi M, Mahanpoora K, Moradi O. Removal of dye molecules from aqueous solution by carbon nanotubes and carbon nanotube functional groups, critical review. RSC Advances. 2017; 7(74):47083-90. [DOI:10.1039/C7RA09377B]

[20] Dehghani M, Naghizadeh A, Derakhshani E. Adsorption of reactive blue 29 dye from aqueous solution by multiwall carbon nanotubes. Desalination and Water Treatment. 2013; 51(40-42):765562. [Doi: 10.1080/19443994.2013.791.772]

[21] Sobhanardakani S, Zandipak R. Removal of anionic dyes (direct blue 106 and acid green 25) from aqueous solutions using Oxidized Multi-Walled Carbon Nanotubes. Iranian Journal of Health Sciences. 2015; 3(3):48-57. [Doi:10.7508/ijhs.2015.3.006]

[22] Ho YS, Chiu WT, Wang CC. Regression analysis for the sorption isotherms of basic dyes on sugarcane dust. Bioresource Technology. 2005; 96(11):1285-91. [DOI:10.1016/j.biortech.2004.10.021]

[23] Annadurai G, Juang SR, Lee JD. Use of cellulose-based wastes for adsorption of dyes from aqueous solutions. Journal of Hazardous Materials. 2002; 92(3):263-74. [DOI:10.1016/S03043894(02)00017-1]

[24] Periasamy K, Namasvayam, C. Process development for removal and recovery of cadmium fromwastewater by a lowcost adsorbent, adsorption rate and equilibrium studies. Industrial \& Engineering Chemistry Research. 1994; 33(2):317-20. [DOI:10.1021/ ie00026a022]

[25] Ghaedi M, Mosallanejad N. Study of competitive adsorption of malachite green and sunset yellow dyes on cadmium hydroxide nanowires loaded on activated carbon. Journal of Industrial and Engineering Chemistry. 2014; 20(3):1085-96. [DOI:10.1016/j. jiec.2013.06.046]

[26] Afkhami A, Moosavi R. Adsorptive removal of Congo red, a carcinogenic textile dye, from aqueous solutions by maghemite nanoparticles. Journal of Hazardous Materials. 2010; 174(1-3): 398-403. [DOI:10.1016/j.jhazmat.2009.09.066] 
